dr. Franc

Križaj

Orgos, d.o.o.

\title{
Vseživljensko izobraževanje med vizijo in utopijo - memorandum
}

\section{SPLOŠNO O MEMORANDUMU}

Svet Evrope je na zasedanju marca leta 2000 sprejel Memorandum o vseživljenskem učenju. Njegov namen je »vzpodbuditi vseevropsko razpravo o vseobsežni strategiji pri uvajanju vseživljenskega učenja na individualni in institucionalni ravni ter na vseh področjih javnega in zasebnega življenja«.

Menim, da vsebina memoranduma ni uresničljiva v sedanjem liberalnem kapitalističnem sistemu, katerega prevladujoči ali celo edini cilj je velika donosnost kapitala. Zdi se mi, kot da je napisan za drugačen, prihodnji čas, čas bolj humanega kapitalizma, ki ga še ni,

Zavedanje potrebnosti vseživljenjskega izobraževanja je se vedno na nizki ravni. ali za čas socializma s človeško podobo, ki ni nikoli zaživel. Zato morda ni odveč vprašanje avtorjem memoranduma, kdaj in kako si predstavljajo uresničenje njegovih temeljnih smernic, kot so:

- vsi, ki živijo v Evropi, bi morali imeti enake možnosti, da se prilagodijo zahtevam družbenega in gospodarskega življenja in da aktivno sodelujejo pri oblikovanju evropske prihodnosti;

- zagotoviti splošen in nenehen dostop do učenja za pridobitev in obnavljanje spretnosti (najbrž znanja in sposobnosti), potrebnih za nenehno sodelovanje $v$ družbi znanja;

- vidno zvišati raven vlaganj $\mathrm{v}$ človeške vire in tako poudariti za Evropo najpomembnejšo prednost - ljudi; združene Evrope dostop do kakovostnega informiranja in svetovanja o učnih možnostih vse življenje;

- Evropa lahko pokaže in mora pokazati, da je možno oboje: doseči dinamično rast in učvrstiti družbeno kohezijo.

Če ne upoštevam svojih pomislekov in sprejmem optimistično vizijo, ki jo ponujajo sestavljalci memoranduma, ne morem mimo ugotovitve, da ni v njem odgovora na to, kdo naj bi ga uresničil, kje dobiti za to potrebna finančna sredstva in navsezadnje, ali si to, kar opredeljuje memorandum, državljani združene Evrope tudi resnično želijo. V razslojeni, sebični, amerikanizirani in izrazito potrošniško usmerjeni evropski družbi je zavest o potrebi po vseživljenskem učenju, večji solidarnosti in vključenosti v urejanje družbenih zadev na dokaj nizki ravni. Zato se sprašujem, kje so in kdo so tisti, ki bodo (ali naj bi) zagotovili vsakemu v združeni Evropi živečemu državljanu enake možnosti za vseživljensko izobraževanje.

Take in podobne formulacije o enakih možnostih za vse in aktivnem sodelovanju pri oblikovanju družbe prihodnosti smo lahko prebrali pred mnogimi leti v programu ZKS in $v$ drugih podobnih deklaracijah iz obdobja samoupravnega socializma. To so tudi ideje mladega Karla Marxa, Ericha Fromma, znanega pripadnika frankfurtske sociološke šole, filozofa in pisatelja Jean-Paula Sartra in mnogih drugih evropskih socialistov iz šestdesetih in sedemdesetih let 20. stoletja. 


\section{KDO NAJ URESNIČI MEMORANDUM}

Iz besedila je možno sklepati, da naj bi bile za uresničenje memoranduma odgovorne predvsem vlade evropskih držav, vodstva gospodarskih in javnih družb ter ponudniki izobraževalnih virov in storitev. Pri nas bi najbrž morala uresničenje te naloge prevzeti ministrstvo za delo, družino in socialne zadeve ter ministrstvo za znanost, izobraževanje in šport. Spričo številnih prednostnih nalog in akutnih denarnih težav, ki jih ima vlada, je nerealno pričakovati, da bo za te potrebe namenila potrebna in primerno visoka denarna sredstva.

Zato lahko od vladnih institucij v teh razmerah pričakujemo samo aktivnosti na deklarativni in normativni ravni. Nekaj je bilo $\mathrm{v}$ tem smislu že narejenega $z$ lanskoletnim sprejemom zakona o nacionalnih poklicnih kvalifikacijah. Zakon namreč omogoča posamezniku javno certificiranje neformalno in naključno (uniformalno) pridobljenega znanja. To je zagotovo velika prednost za vse tiste, ki so si pridobili znanje zunaj formalnih ter javno priznanih izobraževalnih institucij in lahko sedaj tako pridobljeno znanje javno certificirajo.

Širjenje pomena in interesa za neformalno izobraževanje $\mathrm{v}$ gospodarskih subjektih bi morala zagotoviti tudi Gospodarska zbornica Slovenije in druge zbornične organizacije. Iz izkušenj, lastnih in tujih, ugotavljam, da je interes za tovrstno izobraževanje v podjetjih zelo upadel, ker pomenijo izdatki zanj izogibne ali celo odvečne stroške. Zavest o tem, da so

Na normativnem področju bi država lahko spodbudila vse oblike neformalnega izobraževanja z davčnimi olajšavami tako, da bi davčna zakonodaja obravnavala izdatke za neformalno izobraževanje enako kot druga investicijska vlaganja. izdatki za izobraževanje naložba v intelektualni kapital, je značilna samo za nekatera večja podjetja oziroma tista, ki se srečujejo z ostro mednarodno konkurenco. Razlog za takšno stanje je $v$ »ozkem grlu«, ki je tudi $v$ tem primeru (po Petru F. Druckerju) v vrhu družbe oziroma njenem vodilnem managementu. Ne samo, da nima dovolj posluha za izobraževanje sodelavcev, temveč (kar je še huje) tudi sam nima izrazite potrebe po izobraževanju.

\section{KAJ BI MORALI SPREMENITI}

Izkušnje iz mnogih podjetjih kažejo, da se malo najodgovornejših strokovnih in vodstvenih delavcev sistematično dopolnilno izobražuje. Večina za to nima interesa oziroma časa, kot pogosto pravijo, da bi upravičili nezanimanje za izobraževanje. Najbrž so jim za zanesljivo ohranjanje vodstvenega delovnega mesta potrebnejše druge, na izkušnjah temelječe spretnosti, kot so prilagodljivost, vodljivost in lojalnost do nadrejenih. Razlog je tudi v tem, da za najodgovornejša vodstvena delovna mesta praviloma niso izdelani profili potrebnih stro-

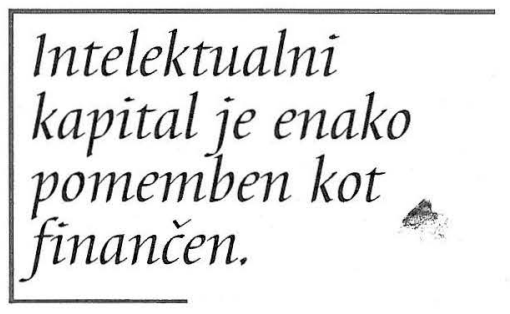
kovnih znanj, izkušenj in osebnostnih lastnosti. Zato najdemo na teh mestih posameznike, ki nimajo potrebne zavesti o pomenu funkcionalnega ter splošnega znanja in tudi ne interesa za stalno poglabljanje ter dopolnjevanje svojega znanja. V takih okoliščinah si ne moremo obetati, da se bo odnos do izobraževanja zaradi memoranduma spremenil.

Uresničenje memoranduma zahteva tudi selekcijo, prenovo in izboljšanje razmer v institucijah, ki se ukvarjajo $s$ funkcionalnim in dopolnilnim izobraževanjem. Z izobraževanjem se ne more ukvarjati vsak, ki meni, da ima drugim kaj koristnega povedati, in ki zna to tudi dobro prodati. 
Menim, da bi morali vsi, ki se ukvarjajo z izobraževanjem in nimajo formalno pridobljenega pedagoškega in andragoškega znanja, pridobiti to znanje in javni certifikat. Zadevo bi morali urediti na normativni ravni, pooblastila za certificiranje predavateljskih sposobnosti pa naj bi podeljeval na primer državni izpitni center, kot je to predvideno v zakonu o nacionalnih poklienih kvalifikacijah (9. člen), ali druga pooblaščena institucija. Seveda bi morali imeti to znanje oziroma si pridobiti certifikat tudi vsi univerzitetni učitelji. Znano je, da večina tega znanja nima, to pa negativno vpliva na kakovost uěnega procesa, odnos do študentov in pripomore k večjemu osipu.

Kljub moji skepsi do uresničljivosti vsebine memoranduma vidim možnosti za njegovo uresničenje $\mathrm{v}$ tistih podjetjih, ki bodo spoznala enakovreden pomen finančnega in intelektualnega kapitala ter njune dolgoročre donosnosti, pa tudi pomen izbire vodstvenih delavcev na vseh ravneh $\mathrm{v}$ skladu $\mathrm{z}$ izdelanimi profili potrebnega strokovnega znanja in osebnostnih lastnosti.

Prve poizkuse o pomenu finančnega in intelektualnega kapitala pri presoji ekonomske donosnosti posamezne družbe je izvedla družba The Boston Consulting Group. Ugotovili so, da pri delovno intenzivnih podjetjih klasični kazalniki donosnosti kapitala (ROI ali ROA) ne kažejo prave slike. Zato je uvedla za delovno intenzivne družbe poleg kazalnika ekonomske uspešnosti (EVA) še kazalnik »Workonomics«, ki temelji na razmerju med dobičkom in stroški na zaposlenega.

\section{SKLEPNE MISLI}

Vsebina memorandum kaže na to, da se v nekaterih institucijah Evropske unije zavedajo nujnega prehoda iz družbe, ki temelji na kratkoročni in maksimalni donosnosti kapitala, $\mathrm{v}$ družbo, ki bo enakovredno obravnavala vlogo kapitala in znanja. Cilj takšne družbe naj bi bil ustvarjanje tolikšnega dobička, ki bo zagotavljal dolgoročni obstoj podjetij, primerno donosnost kapitala in socialno varnost zapo- slenih. V memorandumu pa je čutiti tudi upanje tistih, ki si želijo, da bi prišlo do teh sprememb, a se hkrati zavedajo, da kratkoročno niso možne, ker za to nimajo opore v gospodarskih in političnih institucijah. Prav zaradi neugodnih razmer, ki sem jih omenil, se mi zdi memorandum bolj podoben utopiji kot viziji, čeprav ga podpiram in si močno želim, da bi bil uresničen prej, kot bodo nanj pozabili njegovi najbolj goreči ustvarjalci in zagovorniki.

\section{LITERATURA}

Herrmann, Ned: Das Ganzhirn-konzept für Führungskräfte, Verlag Carl Überreuter, Dunaj, 1997.

Komisija Evropske skupnosti: Memorandum o vseživljenskem učenju (delovno gradivo), SEC (2000)1832, Bruselj, 30. 10. 2000.

Roos Johan idr.: Intelektualni kapital, Inštitut za intelektualni kapital, Ljubljana, 2000.

Uradni list RS: Zakon o nacionalnih poklicnih kvalifikacijah, Ljubljana, 15. 9. 2000. 